\title{
Choosing Unauthorized Migration: Evidence from Return Migrants
}

\author{
Didier Ruedin \\ didier.ruedin@unine.ch \\ and \\ Majlinda Nesturi \\ POST-PRINT \\ This is the final draft after refereeing
}

Published as: Ruedin, D. and Nesturi, M. 2018. 'Choosing to migrate illegally: Evidence from return migrants', International Migration, 56 (4): 235-49. doi:10.1111/imig.12461

https://doi.org/10.1111/imig.12461

\begin{abstract}
We assess who among migrants is likely to choose unauthorized migration. While the literature has addressed reasons for unauthorized migration, we are the first to model individual choice of actual unauthorized migration. By using data from Albanian return migrants, we can ascertain that we capture actual migration - behaviour - rather than intentions to migrate, and respondents have no incentives to hide unauthorized migration as there are no consequences at this stage. At the individual level, unauthorized migration in a context of circular migration is linked to being young and male - interpreted as risk-taking individuals - and being free of social responsibilities like having a partner or children. Social responsibilities appear to moderate the impact of risk-taking on choosing unauthorized migration.
\end{abstract}




\title{
CHOOSING UNAUTHORIZED MIGRATION: EVIDENCE FROM RETURN MIGRANTS
}

\author{
Didier Ruedin \\ University of Neuchâtel and University of the Witwatersrand \\ Swiss Forum for Migration and Population Studies \\ Rue Abram-Louis-Breguet 2 \\ CH - 2000 Neuchâtel \\ +41327183932 \\ didier.ruedin@unine.ch \\ and \\ Majlinda Nesturi \\ Charles University in Prague and INSTAT ${ }^{1}$
}

We assess who among migrants is likely to choose unauthorized migration. While the literature has addressed reasons for unauthorized migration, we are the first to model individual choice of actual unauthorized migration. By using data from Albanian return migrants, we can ascertain that we capture actual migration - behaviour - rather than intentions to migrate, and respondents have no incentives to hide

1 Author contributions: DR and MN designed the study, MN and DR did the analysis, DR and MN wrote the paper. This paper has benefited from work undertaken as part of studies supported by the Department of Sociology, University of Kentucky. We would like to thank Ilka Steiner, Mathias Lerch, Marco Pecoraro, and the reviewer for constructive comments. 
unauthorized migration as there are no consequences at this stage. At the individual level, unauthorized migration in a context of circular migration is linked to being young and male - interpreted as risk-taking individuals - and being free of social responsibilities like having a partner or children. Social responsibilities appear to moderate the impact of risk taking on choosing unauthorized migration.

Keywords: unauthorized migration, irregular migration, undocumented migration, circular migration, risk taking, Albania 


\section{INTRODUCTION}

Migration has become a major issue for many countries in the world, affecting both countries of origin and destination in profound ways. The crossing of borders and residence in the destination country may be formally registered and in accordance with current rules and regulations like having a valid work permit. By contrast, some individuals migrate outside these formal channels - something often referred to as unauthorized or undocumented migration to highlight the lack of adequate documents (Heckmann 2004; Hanson 2007). Several studies have examined why unauthorized migration can and does occur (e.g. Vickstrom 2014; Borodak and Tichit 2014; Massey, Durand, and Pren 2016). They highlight labour demand in the country of destination, migrant networks, and that border enforcement has little impact on the overall flow of migration. Other studies have examined the nature of unauthorized migration - most frequently from the perspective of destination countries (e.g. Bloch 2010; Triandafyllidou 2012). These studies highlight the precarious situation of unauthorized migrants and that they are at the same time 'welcomed' for their economic contributions, especially in the informal economy. Yet little is known about who among migrants chooses unauthorized entry rather than a channel sanctioned by the country of destination. We use data on Albanian return migrants to identify individual characteristics associated with actual unauthorized migration in a context characterized by circular migration.

For a full understanding of migratory patterns it is essential to understand motivations for and processes of migration. In sending countries like Albania internal and international migration have a profound impact on marriage behaviour, fertility, the ageing of society, and the labour market (Lerch 2014; Vullnetari 2015; Agorastakis and 
Sidiropoulos 2007), but we also need to understand the many individuals from South Eastern Europe who left their country when the flow of Syrian refugees in 2015 seemed to provide an opportunity (Juran and Broer 2017). To this end, recent theoretical developments on the reasons to migrate have refined the commonly used notions of push and pull effects. A distinction between aspirations to emigrate, capabilities to move, and opportunities to migrate is drawn (de Haas 2010). We extend this work by arguing that individual characteristics shape whether individuals take up certain opportunities - in this case unauthorized migration. In this article we focus on the mode of border crossing, not the decision to migrate in the first place. Our central argument is that in the context of circular migration unauthorized migration is linked to individual risk-taking: Unauthorized migration does not (only) reflect desperation and push effects, but depends on individual risk assessments which in turn are contingent on age, sex, and social responsibilities in the country of origin - like childcare or dependants. This implies that restrictive immigration systems increase the selection of risk-taking individuals instead of catering for the demands of the economy.

\section{UNAUTHORIZED MIGRATION AND DECISIONS TO MIGRATE}

Traditionally the individual decision to move from one country to another has often been approached with so-called push and pull effects, an evaluation of the positive and negative aspects of the country of origin and the country of destination (Lee 1966). Push

effects are individual and contextual situations that push people to seek 'greener pastures' elsewhere, including poverty, the lack of economic opportunities, natural disasters, climate change, and armed conflict. By contrast, pull effects are perceptions of improved opportunities in a different place, like increased earnings or political stability.

Recent developments in theory have refined these notions of push and pull effects and 
greatly de-emphasized them. A distinction can be drawn between aspirations to emigrate, capabilities to move, and opportunities to migrate (de Haas 2010; Flahaux and de Haas 2016). A person without aspirations to emigrate is unlikely to do so, but we should understand the concept of aspirations in broad terms so that classic push effects like famines cause aspirations to migrate. These recent developments put the capability to move at the centre of the theory - rather than acknowledging it in passing highlighting that an aspiration to emigrate on its own will not result in migration. This can explain why the poorest individuals of a community often do not migrate despite the highest pressure to do so: They are selected out of migration because they cannot afford it, or cannot afford to take the risk of failure inherent in every migration (Chiswick 1999). When they are able to migrate, the poorest tend to migrate under conditions that impede them from improving their well-being and indeed may make them economically worse off (Mosse, Gupta, and Rees 2002; Sloan and Morrison 2016), although overall risks at the household level may still be reduced in the longterm (Stark and Bloom 1985; Massey and Espinosa 1997). Individuals with better education, skills and labour market experience, by contrast, can capture the rewards of migration, and are thus expected to be more likely to migrate (de Haas 2010).

A focus on aspirations and capabilities to move, however, cannot explain why unauthorized migration occurs. Economists highlight asymmetries between the demand for specific labour and supply of authorized migrants with matching qualifications (Borjas 1987). Massey and Espinosa (1997) emphasize the lack of a sufficient number of corresponding work visas as a prerequisite for unauthorized migration. In most Western countries, immigration policies favour highly-skilled workers and family reunion. This pushes low-skilled labour migration towards unauthorized migration channels if there is economic demand (Hanson 2007). The supply of unauthorized 
migrants, however, encourages certain economic arrangements: It is because of the presence of unauthorized immigrants that employers see opportunities to employ them. A sizeable informal economy, like it can be found in South-Eastern Europe, means many opportunities for unauthorized migrants to find work, although unauthorized migrants also find work in the formal economy, and authorized migrants also work in the informal economy (Maroukis, Iglicka, and Gmaj 2011).

Economic differences, however, do not explain why some individuals choose a formal and others an informal channel of migration. Existing research focuses on migration from Mexico to the United States, where in the past almost all migrants crossed the border without documents or using a tourist visa to work (Massey and Espinosa 1997). Empirically, this means that existing research is in a poor position to distinguish between the decision to emigrate and the decision to do so as an unauthorized migrant. Despite these limitations, some contributions like Massey and Espinosa examine the two modes in separate models - contrasting both with not migrating at all - but they do not examine individual-level variables behind the differences. Related research on the first unauthorized trip Mexicans take to the United States highlights migrant networks: Having a family member who migrated to the United States increases the odds of Mexicans choosing unauthorized migration compared to not migrating at all (Massey and Riosmena 2010), while individuals who own land or a business in Mexico are less likely to leave, as are those in skilled occupations (Massey and Espinosa 1997; Massey, Durand, and Pren 2016). The costs of migration and border enforcement do not seem to affect unauthorized migration (Massey and Espinosa 1997; Massey and Riosmena 2010; Massey, Durand, and Pren 2016).

As far as we could determine, only one study models the mode of migration. Ryo (2013) focuses on the intent of unauthorized migration and examines economic variables 
(interpreted as the cost-benefit analysis highlighted in neoclassical economic theory) as well as normative variables around the legitimacy of (immigration) laws. She includes perceptions of the danger of border crossing as an economic consideration. Ryo's research highlights that the intent to cross borders illegally is higher for younger individuals and those who are not head of households. Rather than treating these as control variables, we argue that these factors are central for understanding why individuals choose unauthorized migration: They reflect the extent to which individuals are risk-taking. After all, the variables examined by Ryo capture perceptions before migrants depart, and not necessarily the objective economic costs.

\section{MIGRATION IN ALBANIA}

To examine the choice of unauthorized migration, we study the situation in Albania, a small country in South-Eastern Europe. Between 1946 and 1992 Albania was ruled by a communist regime under the leadership of Enver Hoxha and the Party of Labour. During the communist era, the country experienced isolation from much of the world, including most other communist countries. The communist regime heavily restricted the internal and external mobility of Albanians. Very few (privileged) Albanians were allowed to travel yet alone live abroad. The transition to a market economy after the end of the communist regime has brought economic growth - recently despite the economic crisis in Europe - but the GDP per capita of Albania remains around a third of the European average. Levels of unemployment are lower than in many countries in the region, but youth unemployment is an important problem. Despite a shift towards services, agriculture remains one of the most important sectors in the country (World Bank 2015).

After the end of communist rule travelling restrictions were lifted in 1993, and the 
country has experienced substantial internal migration towards major cities and international migration. The most common destination countries for Albanians are Italy and Greece with which Albania shares a border (Mai and Paladini 2013; Galanxhi et al. 2014; Lerch 2014). Initially both internal and international migration were interpreted as a necessary correction after the communist restrictions (Maroukis and Gema 2013; Galanxhi et al. 2004), but the trend shows no sign of abating (Galanxhi et al. 2014). With many Albanians living abroad, the country's population has decreased from 3.3 million in 1991 to under 2.9 million in 2014 (World Bank 2016).

However, circular migration is commonplace in Albania: repeated stays abroad interceded by returns to the country (Stampini, Carletto, and Davis 2008; Vullnetari 2015; see Vathi, Duci, and Dhembo 2016 for a discussion of the challenges of returning migrants in Albania). When working abroad, the majority of Albanians work in lowskilled and unskilled sectors of the economy, often in the informal economy. In qualitative research, Albanians often present (temporary) emigration as a 'solution' to their problems in the country, rarely as a choice. Lack of opportunities, unemployment and under-employment are often cited as problems (Mai and Paladini 2013). Qualitative evidence also suggests that much of Albanian migration is circular in character because the involved individuals prefer to maintain their base in Albania (Maroukis and Gema 2013). A (temporary) return to Albania may occur for many reasons, but usually is caused by a lack of employment. After the Great Recession affected Greece and Italy in 2008, the number of Albanians returning increased (Galanxhi et al. 2014) and the number of apprehensions of unauthorized migrants in Greece decreased (Triandafyllidou et al. 2014). Many return migrants, however, expressed a clear intent to emigrate again when the opportunity arises (Maroukis and Gema 2013), a typical sign of circular migration. 
Most Albanians who emigrate are of working age, and a majority are male. This gender imbalance is linked to a patriarchal family model that remains dominant in Albania, where men are often the breadwinners (Filipi et al. 2014). The gender imbalance, however, has decreased in comparison to the 1990s (Galanxhi et al. 2014). In line with the patriarchal family model, the most common reason Albanian women give for emigration is family reunification, usually linked to a male worker having found a relatively stable opportunity abroad. Where work opportunities are clearly more temporary, families often choose to leave the woman and possible children in Albania, frequently supported by members of the wider family. Despite an economy not heavily affected by the 2008 financial crisis, many young adults only perceive limited economic opportunities in the country and seek opportunities abroad (Vullnetari 2015).

In the early 1990s, it was nearly impossible for Albanians to obtain work visas, leading to unauthorized migration (Chindea et al. 2008). In 1996, however, Albania and Greece signed a bilateral employment agreement, followed by one between Albania and Italy in 1997. These agreements brought legal opportunities for some workers, and introduced the possibility of family reunification and studying abroad. Two decades after these changes and legal possibilities to work abroad, unauthorized migration remains a common form for Albanians, frequently referred to as characteristic of Albanian migration (Barjaba and King 2005; Maroukis 2012; Vullnetari 2015). Indeed, Albanian continues to be among the most common nationalities found to be illegally present in the European Union (Sabbati and Poptcheva 2015). The high rate of unauthorized migration reflects opportunities due to geographical proximity and lenient enforcement in Greece (compare Eschbach et al. 1999; Massey, Durand, and Pren 2016 on the effects of strong enforcement in the case of the Mexican—US border). There are no incentives like potential access to citizenship in the long term. A visa liberalisation regime in 
December 2010 seems to have reduced the number of individuals apprehended for illegal border crossing to Greece to some degree (Triandafyllidou et al. 2014), but unauthorized migration has far from disappeared.

While the communist past and its geographical proximity to countries with lenient border controls may seem to limit the generalizability of findings from Albania to other post-communist transitions, we argue that the case of Albania merely provides an amplification of a more general phenomenon. The emigration from Albania after the end of the communist regime may have been more intensive than in other postcommunist countries (Barjaba 2000), but such ‘corrections' are normal (Maroukis and Gema 2013). Like in other sending countries, remittances play an important role in Albania, and there is widespread belief that there are 'no' economic opportunities in the country (Mai and Paladini 2013). Emigration and remittances coexist with large-scale urbanization and related demographic transformations (Galanxhi et al. 2014).

The focus on Albania allows us to disentangle factors associated with the decision to emigrate from factors associated with the choice of unauthorized migration. We examine the contrast between authorized and unauthorized migration among a sample of migrants and do not compare these migrants with non-migrants who chose to remain in Albania. Empirically, the case has the advantage of having a sufficient number of unauthorized migrants: neither as dominant as in the Mexican-US case in the past, nor as rare as in most Western European countries. We also add fresh data to a literature dominated by the excellent Mexican Migration Project (MMP), and situate unauthorized migration in a contemporary framework of migration decisions (de Haas 2010).

Unauthorized migration comprises unauthorized entry and more commonly residence without adequate permits, such as when migrants use a tourist visa to enter a country for 
work purposes as Albanians in Greece and Italy often do. We refer to a choice of unauthorized migration to emphasize that technically legal entry is a - in many cases perhaps hypothetical - possibility and that the migrants in question are not so-called forced migrants. In the case of Albania, workers usually need a valid work contract to obtain a visa, something difficult to obtain for work in the informal economy. In the context of unauthorized migration from Mexico to the United States scholars often highlight that unauthorized migrants do apply for work visas, but cannot obtain them quickly enough to respond to current opportunities and choose unauthorized migration in the meantime (Hanson 2007). We still consider this a choice - they could have waited, and many Mexicans do not seek unauthorized work in the United States - just like in the present case of Albania. In Albania, however, many migrants never even try to obtain a legal permit, often because they lack a concrete job offer.

We focus on unauthorized migration as a particular kind of opportunity to migrate; once aspirations and capabilities align, individuals still have a choice of different modes of migration. The focus is on unauthorized migration as opposed to authorized migration and as opposed to over-stayers who enter a country legally. Individuals who choose not to migrate are not considered; without evidence to the contrary, we assume that the availability of illegal channels as such does not affect aspirations to emigrate. We argue that we can best understand unauthorized migration as a form of risk taking (compare Jaeger et al. 2010 on risk attitudes and propensities to migrate). From this general intuition we derive three expectations that spell out individual characteristics linked to increased risk-taking behaviour relevant to migration, acknowledging that these are relatively crude proxies of the propensity of being risk-taking at the individual level, although proxies that are relatively robust (Williams and Baláž 2012; Mather et al. 2012; Croson and Gneezy 2009). We have no indication that the ability to secure work 
permits is associated with the individual-level variables examined in this article.

First, individuals with social responsibilities like being married or having children (family constraints) are likely to consider their close ones and are less likely to engage in risky behaviour (Zaiceva and Zimmermann 2008). That said, with social responsibilities the pressure to gain additional income may be increased, but we expect the overall effect to be a reduced likelihood to engage in risky behaviour (compare Stark and Bloom 1985; Massey, Durand, and Pren 2016). Second and third, risk taking reduces with increased age, and is more common among men than women (Kam 2012; Croson and Gneezy 2009). These are generic associations between individual characteristics and circumstances on the one hand, and risk taking on the other, and future research should illuminate these associations further, for instance by using data covering personality types (see Schwartz et al. 2014 for a generic frame).

Expectation 1: Individuals without social responsibilities are more likely to choose unauthorized migration.

Expectation 2: Younger individuals are more likely to choose unauthorized migration.

Expectation 3: Men are more likely to choose unauthorized migration.

Moreover, we consider statistical interactions between the three identified groups to examine whether there are particular subgroups that are especially prone to choosing unauthorized migration. If there are significant statistical interactions, we expect them to be reinforcing in the case of younger individuals without responsibilities (particularly risk-taking), while the effects between being male and having responsibilities may be reducing each other to some extent. We do not have strong expectations as to which 
variable is likely to dominate, nor whether statistical interactions are likely to be substantively consequential for the phenomenon under observation.

\section{DATA AND METHODS}

We use individual-level data from the 2013 Return Migration and Reintegration in Albania survey (refer to Filipi et al. 2014 for a technical report). There are three significant advantages of using data on return migrants: First, we can disentangle determinants of migration (or aspirations to migrate) from the choice of unauthorized migration. All the individuals in our sample did migrate. Second, we can ascertain that actual migration - behaviour - is captured rather than intentions to migrate. The data focus on the last migration experience in cases of so-called multiple or circular migration. Third, by surveying individuals who have returned, respondents have no incentives to hide unauthorized migration as there are no consequences at this stage. This is a great advantage over surveys in the country of destination. A disadvantage is that we do not capture permanent migration to other countries, and cannot establish whether the choice of unauthorized migration is different for those who intend to emigrate permanently. Assuming that unauthorized migration is more common in circular migration, we will overestimate the incidence of unauthorized migration generally, but not in the case of circular migration.

The Return Migration and Reintegration in Albania survey used the 2011 Population and Housing Census as the sampling frame, drawing from individuals who have returned to Albania after 2009. Proportional probability to size-systematic sampling was used, and the sampling frame includes all Albanians aged 18 or over who returned to Albania either voluntarily or involuntarily. The inclusion of involuntary return seems important to us, because it reflects the risk inherent in unauthorized migration, despite 
efforts to blend in when abroad (Kokkali 2015). Both long-term and short-term migration was considered, as was temporary and permanent return. When the preselected individual was not present, he or she was replaced by the next individual in the same household who fulfilled the conditions (randomly selected), but the sample includes only one respondent per household. The response rate of the survey is $91 \%$, and there are 1,878 individuals in the dataset. The survey asks about the situation before leaving Albania, the experience in the last country of destination, and post-return conditions - the analysis in this article uses largely data from the first module which includes demographic and social characteristics, reasons for leaving Albania, the social and financial situation, the composition of the household, education, skills, and professional experience.

Our analytical strategy is to use these data on return migrants in Albania to find out who chose unauthorized migration as part of their migration experience. Our outcome variable draws on the following question: “Under what conditions did you go abroad?” which has three response categories ("with official documents", 46\% of respondents; “no official documents", 46\% of respondents; and "with false documents”, $8 \%$ of respondents). We collapsed this into a binary variable distinguishing between unauthorized migration (54\% of respondents) and authorized migration (46\% of respondents). The responses given are plausible inasmuch individuals travelling without legal documents with very rare exceptions do not report having travelled by aeroplane, in which case travelling without official documents seems implausible. Similarly, being expelled as a reason for return is almost exclusive for those indicating a lack of official documents. We use logistic regression analysis to statistically explain individual choice of unauthorized migration when emigrating. Three predictor variables are used. Social responsibilities are captured with a binary variable, coded 1 for married individuals or 
those with dependent children (49\% of respondents) and 0 otherwise. Sex is captured using a binary variable, and age as a continuous variable. $74 \%$ of the return migrants are men, and the median age before emigrating was 27 years. With a median age of 26 years, men were slightly younger than women with a median age of 30 years.

Several control variables are included. The level of education was measured in a categorical way in the survey, but converted into (typical) years of schooling following the current Albanian education system. To capture differences in preparations for working abroad (see Sladkova 2016 for qualitative evidence that such resources are important), a binary variable was created, coded 1 for individuals who know at least one foreign language (28\% of respondents) or have completed vocational training before leaving Albania (5\% of respondents). A separate variable captures whether individuals worked before migrating (19\% of respondents). Three variables are used to capture living conditions before migrating. The first measures precarious work conditions, which was coded 1 if the individual was self-employed, unemployed, a student, or employed with a fixed-term contract ( $80 \%$ of respondents). The second captures the self-assessed financial situation (49\% in a poor situation), while the third looks at the material situation by asking whether respondents owned a range of durable goods. In a different variable, we classified reasons to migrate into push factors (lack of employment, lack of housing, general insecurity in Albania, social reasons, medical reasons; coded +1) and pull factors (employment offer abroad, better job opportunities, better income prospects abroad, to join family, to join friends; coded -1) and then added up to capture whether push factors dominate over pull factors for an individual's choice to migrate. For instance, for an individual who mentioned lack of employment $(+1)$, lack of housing (+1), and better job opportunities abroad (-1), the sum is +1 , a slight tendency towards push factors. This control variable was constructed with reference to 
theory (Lee 1966). In 74\% of cases pull factors dominate in the sense that the sum is smaller than zero, but we refrain from interpreting this variable as a scale because we cannot assert that no important components are missing. Finally, to capture period effects, a binary variable measures whether an individual left Albania after the onset of the financial crisis in 2008 (36\% of respondents).

\section{FINDINGS}

For Albanians, the most common countries of destination are Greece and Italy. Of the returnees, 54\% report having crossed the borders without or with forged legal documents. We have no expectation that this figure translates to other contexts because border control and economic opportunities in the country of destination differ (compare Eschbach et al. 1999 on border enforcement), but we argue that the underlying mechanisms are likely to apply to other similar contexts dominated by circular migration. Table 1 presents bivariate evidence in support of the expectations: Individuals without social responsibilities like children and dependants are more likely to choose unauthorized migration, and men are much more likely to do so than women. These gender differences are similar in size to what is reported for unauthorized Mexican-US migration (Valdez-Suiter, Rosas-López, and Pagaza 2007). The median age of unauthorized migrants is lower than for authorized migrants, bearing in mind that migrants tend to be young in either case.

[TABLE 1 AROUND HERE]

For the control variables, the associations are as expected, suggesting that they 
constitute alternative influences on the choice of unauthorized migration. For instance, the typical unauthorized migrant has eight years of education (58\%), while for authorized migration, twelve years are the norm. This pattern corresponds to unauthorized Mexican—US migration (Valdez-Suiter, Rosas-López, and Pagaza 2007; Ryo 2013). Similarly, we observe that most migrants were not particularly well prepared for their venture abroad in the sense that only $30 \%$ had knowledge of a foreign language or completed vocational training. This percentage is lower among unauthorized migrants (21\%). This may be linked to the fact that a clear majority of unauthorized migrants were not in regular work before migrating (84\%). Using an alternative measure to capture the security of the position before migrating, we estimate that $80 \%$ were in a precarious situation, but among unauthorized migrants the figure was $89 \%$. A similar picture can be drawn when property ownership and the financial situation are focused on rather than job security - unauthorized migrants report having been in a worse situation than those choosing authorized migration.

Multivariate analysis: Sex, age, and social responsibilities are associated with unauthorized migration

Having found support for the expectations in bivariate analysis, we turn to multivariate regression models. The first model presented in Table 2 includes the predictor variables along with controls for the financial situation before migrating and preparations, namely whether individuals had knowledge of a foreign language or vocational training. The model indicates that individuals with social responsibilities are significantly less likely to choose unauthorized migration, as are older individuals. The reduction is an average 8 per cent across models 1 to 4 for those with responsibilities. Additional analysis in 
supplement S6 suggests that dependent children may contribute more to this result, although the results are not statistically significant. With regard to age, the reduction is an average 2 per cent across models 1 to 4 . This predicted effect refers to the difference of one year, and we should bear in mind that most migrants are young, thus we are looking at a substantially important difference. Moreover, men are around 4 times more likely to choose unauthorized migration, supporting the intuition that individual risk taking is a relevant factor.

[TABLE 2 AROUND HERE]

Models 2 to 4 in Table 2 each add one control variable to demonstrate the robustness of the findings. The addition of these variables does not increase the model fit significantly, nor are the predictor variables affected substantively. For reasons of multicollinearity and lack of strong theoretical reasons we have refrained from adding additional variables in the models presented here; the models presented in Table 2 have a VIF less than 1.73 suggesting that multicollinearity is not a concern.

Additional models in the supplement highlight the robustness of the results presented and open up possible avenues for further research. The models in Table S1 include nonlinear terms for age and years of education, indicating that the statistical effects of age and education decrease slightly with greater age and levels of education. When implemented as three levels of education, the difference between low and medium levels of education is substantively larger. These considerations of non-linearity, however, do not seem to add additional information with regard to our main variables. In Table S2, we add network variables: individuals who emigrate to join members of 
their family are much less likely to choose unauthorized migration, while individuals who emigrate to join friends and colleagues are more likely to choose unauthorized migration. These results are in line with the expectation on social responsibilities and research on Mexican-US migration (Massey and Espinosa 1997), but are not elaborated in the main text for reasons of multicollinearity (VIF $>5$ ) and because we could not ascertain the quality of the self-reported network variables. Taken together, the models in Table 2 and the supplement are robust evidence that unauthorized migration is shaped by the variables we use to measure social responsibilities and risk taking. Separate models for Greece and Italy in supplement S4 and S5 confirm the general findings, but because of the smaller number of observations the variable for social responsibilities and the control variable for education are not statistically significant. The sign of social responsibilities in the models for Italy is reversed, but with a sample of 441 respondents we lack sufficient observations to investigate if there are real differences and why.

Older individuals are more influenced by social responsibilities

In a final step, we examine whether the two explanations - social responsibilities and risk taking - interact in a particular way. The basic intuition is that the effect of age is larger for individuals with social responsibilities than for those without responsibilities. Figure 1 shows the interaction effect between age and social responsibilities in graphical form. The y-axis shows the predicted probabilities of choosing unauthorized migration; the $\mathrm{x}$-axis shows the age at which individuals migrated. The two lines indicate the relationship between these two variables once for those with social responsibilities (solid line) and once for those without (dotted line). We can see that the two lines are in 
the same direction, but are not parallel. This indicates that older individuals are predicted to be less likely to choose unauthorized migration in both groups, but this declining tendency is stronger for those with social responsibilities. The addition of this interaction effect to model 2 substantially increases the model fit.

\section{[FIGURE 1 AROUND HERE]}

For the relationship between social responsibilities and sex, by contrast, it is difficult to formulate a clear overall expectation given that the two effects are in the opposite direction and may cancel each other out. Perhaps unsurprisingly, this second interaction term does not add significantly to the model fit. Table S3 in the supplement presents several models, in none of which the interaction term is statistically significant. Further research is necessary to disentangle the two stipulated effects to address the potential relationship between the two. These limitations notwithstanding, this section lends further support to the expectations that social responsibilities and risk taking are likely and interrelated - mechanisms in shaping the choice of unauthorized migration. The interaction effect presented in Figure 1 highlights that having social responsibilities can moderate the predicted effects of being risk-taking (age).

\section{DISCUSSION, POLICY IMPLICATIONS, AND CONCLUSION}

This article looked at the choice of unauthorized migration - without legal documents, or with documents that are forged - in the context of Albanian migration to Greece and Italy. We know little as to why individuals choose this form of migration, particularly outside of the Mexican-US context. By drawing on data on return migrants from 
Albania, we could elucidate two likely mechanisms that encourage unauthorized migration at the individual level: not having social responsibilities, and being risktaking. Only by having a better understanding of the mechanism that encourage unauthorized migration it is possible to better grasp the nature of this particular form of migration. While destination countries may prefer formal migration because it is controllable and subject to policy interventions, it is important to understand the nature of unauthorized migration - particularly because it is outside the realm of state control.

The analyses confirmed that in a context characterized by circular migration, lenient enforcement, and a large informal sector in the country of destination, individuals with social responsibilities and family constraints are less likely to choose unauthorized migration. However, we argue that the main driver behind the choice of unauthorized migration over authorized migration is being risk-taking. This personality characteristic was approached using young age and being male as indicators (Williams and Baláž 2012; Mather et al. 2012), and further research with dedicated survey questions is necessary to fully understand which sections of society are particularly prone to unauthorized migration. Our findings imply that restrictive immigration policies and enforcement increase the selection of risk-taking individuals potentially at the cost of economic demand for (low-skilled) immigrants (compare Chiswick 1999). Social responsibilities seem to moderate the influence of being risk-taking in the case of age, while for sex differences the picture was unclear - something which may be due to overall effects that cancel each other out. All the reported associations are robust to the inclusion of several control variables, including period effects.

While individual characteristics appear to be linked with the choice of unauthorized migration, we should bear in mind that one reason for unauthorized migration is that without a concrete job offer, legal channels to migrate tend not to be available. 
Opportunities to migrate legally to search for work may greatly reduce the incidence of unauthorized migration - especially for young men without social responsibility -, and with that reduce the vulnerability of unauthorized migrants while increasing state control over parts of the migrant population. The fact that some individuals take up opportunities of unauthorized migration highlights that formal migration policies may fail to regulate some migrant populations because they operate outside state control.

Rather than focusing on push and pull effects, as it (still) often done in the literature, in our view we should regard migration decisions and the choice of unauthorized migration in the framework of aspirations, capabilities and opportunities (de Haas 2010; Flahaux and de Haas 2016). What this article adds to recent developments on migration decisions is the insight that risk assessments seem to play an important role (Zaiceva and Zimmermann 2008) - at the stage of opportunities and the choice of the mode of migration (compare Ryo 2013 who used intentions to migrate rather than actual migration behaviour). The nature of the data used in this article - return migrants means that by definition only individuals with aspirations, capabilities, and opportunities to migrate are covered: actual migrants. This means that we can disentangle determinants of migration from those of unauthorized migration. The case of Albanian return migrants is particularly instructive here as it includes enough variation in the key variables and is relatively free from social desirability biases in the survey.

While the analysis is based on a case dominated by circular migration and characterized by relatively high levels of unauthorized migration, we argue that the underlying mechanisms in the choice of unauthorized migration are likely to be comparable to other contexts - probably except for so-called forced migration - although depending on the border involved the opportunities of unauthorized migration are likely be drastically 
reduced (e.g. Eschbach et al. 1999). We expect that in other cases, too, the most risktaking individuals - particularly young men - are most prone to unauthorized migration, especially if legal entry is made difficult in the country of destination. For instance, we expect our findings to apply to immigrants from South Eastern Europe who took opportunity of the substantive flow of refugees from Syria to Germany after 2015 (Juran and Broer 2017). According to our interpretation, this substantive flow of refugees has lowered the risks inherent in unauthorized migration (Chiswick 1999), encouraging individuals who would otherwise consider such an endeavour as 'too risky', although it remains particularly those we identified as risk-taking - young men without social responsibilities - who take up the opportunity (Juran and Broer 2017). Further research in this area is necessary to better understand the nature of unauthorized migration and to ascertain that the findings from Albania translate more widely, although they resonate findings on unauthorized migration in the Mexican-US case where the choice of unauthorized migration cannot be distinguished so clearly from the choice of migration more generally.

Interestingly, in many ways individuals who choose unauthorized migration resemble those choosing authorized migration, notably with regard to education. This similarity resonates research on unauthorized migrants in Moldova that highlights that a key difference between authorized and unauthorized migrants is the length of each individual stay in the destination country - not the overall time in the destination country (Borodak and Tichit 2014). In the case of the Mexican-US border, too, similarities between authorized and unauthorized migrants have been highlighted (Massey and Espinosa 1997). This finding is entirely compatible with our view that the choice of unauthorized migration is a reflection of risk taking and (lack of) social responsibilities, and more research on the length of stay and its link to unauthorized 
migration is warranted, especially outside the Mexican-US case. Further research is also necessary on the nature of social responsibilities, using more refined variables than those in the data we used. Despite being more risk-taking, the involved unauthorized migrants are likely to minimize the risk of deportation at the borders, especially at borders with stricter control than in the case of Albania. The results presented here are also compatible with existing studies that highlight the role of attitudes towards legal norms (Ryo 2013), or social networks (Massey and Riosmena 2010; Sladkova 2016). Further research is necessary to examine how these different mechanisms - being risktaking, having social responsibilities, attitudes and norms - interact with economic assessments and one another.

Data from return migrants seem suitable to address these questions, particularly because actual behaviour rather than intentions to migrate are captured. Indeed, the focus on return migrants as a method is often overlooked in the literature and by policymakers, and deserves more attention, especially now that middle income countries are increasingly (able to) produce high quality surveys on migrants. Different to the common surveys on intentions to migrate, however, surveys on return migrants include data on (reported) actual behaviour. Contrary to surveys in countries of destination, data on return migrants are likely to free of social desirability bias on this particular question given that there is no risk of deportation. As a limitation, however, truly permanent patterns of migration are not covered, limiting the generalizability of results to some degree, just like surveys in the country of destination may underestimate the incidence of circular migration. Contemporary migration, however, often takes the form of repeated migration (Maroukis and Gema 2013).

In this article we have shown that having social responsibilities and being risk-taking approached through age and sex - are good predictors of choosing unauthorized 
migration. Seen this way, the article contributes to understanding unauthorized migrants - a group of migrants often elusive to scholars and policymakers. Future research should pay more attention to how the outlined mechanisms interact with contextual factors like the economic situation, border control, or possible period effects beyond those addressed in this article. We expect that these external factors have a substantive effect on the rate of unauthorized migration, but not necessary on the underlying mechanisms. By taking into consideration the role of risk taking, we can refine recent developments in our understanding of migration decisions, which will ultimately lead to a better understanding of population dynamics given that in many countries the impact of migration on population growth or indeed decline constitutes a significant source of uncertainty. 


\section{REFERENCES}

Agorastakis, Michalis, and Giorgos Sidiropoulos. 2007. "Population Change Due to Geographic Mobility in Albania, 1989-2001, and the Repercussions of Internal Migration for the Enlargement of Tirana.” Population, Space and Place 13 (6):471-481. https://doi.org/10.1002/psp.463.

Barjaba, Kosta. 2000. “Contemporary Patterns in Albanian Emigration.” SEER: Journal for Labour and Social Affairs in Eastern Europe 3 (2):57-64.

Barjaba, Kosta, and Russel King. 2005. "Introducing and Theorising Albanian Migration.” In The New Albanian Migration, edited by Russell King, Nicola Mai, and Stephanie Schwandner-Sievers. Eastbourne: Sussex Academic Press.

Bloch, Alice. 2010. "The Right to Rights? Undocumented Migrants from Zimbabwe Living in South Africa.” Sociology 44 (2):233-50. https://doi.org/10.1177/0038038509357209.

Borjas, George J. 1987. "Self-Selection and the Earnings of Immigrants." American Economic Review 77:531-53.

Borodak, Daniela, and Ariane Tichit. 2014. "Should We Stay or Should We Go? Irregular Migration and Duration of Stay: The Case of Moldovan Migrants.” Migration Studies 2 (3):415-47. https://doi.org/10.1093/migration/mnt016.

Chindea, Alin, Magdalena Majkowska-Tomkin, Heikki Mattila, and Isabel Pastor. 2008. Migration in Albania: A Country Profile 2008. Geneva: IOM. https://publications.iom.int/books/migration-albania-country-profile-2008.

Chiswick, Barry R. 1999. “Are Immigrants Favorably Self-Selected?” American Economic Review 89 (2):181-85.

Croson, Rachel, and Uri Gneezy. 2009. “Gender Differences in Preferences.” Journal of Economic Literature, 448-474.

Eschbach, Karl, Jacqueline Hagan, Nestor Rodriguez, Ruben Hernandez-Leon, and Stanley Bailey. 1999. "Death at the Border." The International Migration Review 33 (2):430-54. https://doi.org/10.2307/2547703.

Filipi, Gjergji, Emira Galanxhi, Majlinda Nesturi, and Teuta Grazhdani. 2014. Return Migration and Reintegration in Albania 2013. Tirana: INSTAT \& IOM. http://www.instat.gov.al/media/255982/return_migration_and_reintegration_in_a lbania_2013.pdf.

Flahaux, Marie-Laurence, and Hein de Haas. 2016. “African Migration: Trends, Patterns, Drivers.” Comparative Migration Studies 4 (1):1. https://doi.org/10.1186/s40878-015-0015-6.

Galanxhi, Emira, Elena Misja, Desareta Lameborshi, Mathias Lerch, Philippe Wanner, and Janine Dahinden. 2004. "Migration in Albania.” Population and Housing Census 2001. Tirana: INSTAT.

Galanxhi, Emira, Majlinda Nesturi, Ledia Thomo, Elira Jorgoni, and Didier Ruedin. 2014. "Migration in Albania." Tirana: INSTAT. http://www.instat.gov.al/media/242045/migration_in_albania.pdf.

Haas, Hein de. 2010. "Migration Transitions: A Theoretical and Empirical Inquiry into the Developmental Drivers of International Migration.” IMI Working Papers 24:1-49.

Hanson, Gordon Howard. 2007. “The Economic Logic of Illegal Immigration.” Council on Foreign Relations 26:1-52.

Heckmann, Friedrich. 2004. "Illegal Migration: What Can We Know And What Can We 
Explain? The Case of Germany.” International Migration Review 38 (3):110325. https://doi.org/10.1111/j.1747-7379.2004.tb00230.x.

Jaeger, David A., Thomas Dohmen, Armin Falk, David Huffman, Uwe Sunde, and Holger Bonin. 2010. "Direct Evidence on Risk Attitudes and Migration.” The Review of Economics and Statistics 92 (3):684-689.

Juran, Sabrina, and P. Niclas Broer. 2017. "A Profile of Germany's Refugee Populations.” Population and Development Review 43 (1):149-57. https://doi.org/10.1111/padr.12042.

Kam, Cindy D. 2012. "Risk Attitudes and Political Participation.” American Journal of Political Science $56 \quad$ (4):817-36. https://doi.org/10.1111/j.15405907.2012.00605.x.

Kokkali, Ifigeneia. 2015. “Albanian Immigrants in the Greek City: Spatial 'invisibility’ and Identity Management as a Strategy of Adaption.” In Migration in the Southern Balkans: From Ottoman Territory to Globalized Nation States, edited by Hans Vermeulen, Martin Bladwin-Edwards, and Riki Van Boeschoten. New York: Springer.

Lee, Everett S. 1966. “A Theory of Migration.” Demography 3 (1):47-57. https://doi.org/10.2307/2060063.

Lerch, Mathias. 2014. "The Role of Migration in the Urban Transition: A Demonstration From Albania.” Demography 51 (4):1527-50. https://doi.org/10.1007/s13524014-0315-8.

Mai, Nicola, and Christiana Paladini. 2013. "Flexible Circularities: Integration, Return and Socio-Economic Instability within Albanian Migration to Italy.” In Circular Migration between Europe and Its Neighbourhood, edited by Anna Triandafyllidou. Oxford: Oxford University Press.

Maroukis, Thanos. 2012. "Irregular Migration in Greece: Size and Features, Causes and Discourses.” In Irregular Migration in Europe: Myths and Realities, edited by Anna Triandafyllidou, 93-114. Farnham: Ashgate.

Maroukis, Thanos, and Edi Gema. 2013. “Albanian Circular Migration in Greece: Beyond the State?" In Circular Migration between Europe and Its Neighbourhood, edited by Anna Triandafyllidou. Oxford: Oxford University Press.

Maroukis, Thanos, Krystyna Iglicka, and Katarzyna Gmaj. 2011. "Irregular Migration and Informal Economy in Southern and Central-Eastern Europe: Breaking the Vicious Cycle?” International Migration 49 (5):129-56. https://doi.org/10.1111/j.1468-2435.2011.00709.x.

Massey, Douglas S., Jorge Durand, and Karen A. Pren. 2016. "Why Border Enforcement Backfired.” American Journal of Sociology 121 (5):1557-1600. https://doi.org/10.1086/684200.

Massey, Douglas S., and Kristin E. Espinosa. 1997. "What's Driving Mexico-U.S. Migration? A Theoretical, Empirical, and Policy Analysis.” American Journal of Sociology 102 (4):939-99.

Massey, Douglas S., and Fernando Riosmena. 2010. "Undocumented Migration from Latin America in an Era of Rising U.S. Enforcement." The ANNALS of the American Academy of Political and Social Science 630 (1):294-321. https://doi.org/10.1177/0002716210368114.

Mather, Mara, Nina Mazar, Marissa A. Gorlick, Nichole R. Lighthall, Jessica Burgeno, Andrej Schoeke, and Dan Ariely. 2012. "Risk Preferences and Aging: The 'Certainty Effect' in Older Adults’ Decision Making.” Psychology and Aging 27 (4):801. 
Mosse, D., S. Gupta, and J. Rees. 2002. "Brokered Livelihoods: Debt, Labour Migration and Development in Tribal Western India.” In Labour Mobility and Rural Society, edited by A. de Haan and B Rogaly. London: Frank Cass.

Ryo, Emily. 2013. "Deciding to Cross Norms and Economics of Unauthorized Migration.” American Sociological Review 78 (4):574-603. https://doi.org/10.1177/0003122413487904.

Sabbati, Giulio, and Eva-Maria Poptcheva. 2015. "Irregular Immigration in the EU: Facts and Figures." European Parliamentary Research Service Briefing April (PE 554.202):1-4.

Schwartz, Shalom H., Gian Vittorio Caprara, Michele Vecchione, Paul Bain, Gabriel Bianchi, Maria Giovanna Caprara, Jan Cieciuch, et al. 2014. "Basic Personal Values Underlie and Give Coherence to Political Values: A Cross National Study in 15 Countries.” Political Behavior 36 (4):899-930. https://doi.org/10.1007/s11109-013-9255-z.

Sladkova, Jana. 2016. "Stratification of Undocumented Migrant Journeys: Honduran Case.” International Migration $54 \quad$ (1):84-99. https://doi.org/10.1111/imig.12141.

Sloan, Michael K., and Philip S. Morrison. 2016. "The Post-Move Satisfaction of Internal Migrants.” Migration Studies 4 (1):97-115. https://doi.org/10.1093/migration/mnv013.

Stampini, Marco, Calogero Carletto, and Benjamin Davis. 2008. "International Migration from Albania: The Role of Family Networks and Previous Experience." Eastern European Economics $46 \quad$ (2):50-87. https://doi.org/10.2753/EEE0012-8775460203.

Stark, Oded, and David E. Bloom. 1985. “The New Economics of Labor Migration.” The American Economic Review, 173-178.

Triandafyllidou, Anna, ed. 2012. Irregular Migration in Europe: Myths and Realities. Farnham: Ashgate.

Triandafyllidou, Anna, Michaela Maroufof, Angeliki Dimitriadi, and Kleopatra Yousef. 2014. "Migration in Greece: Recent Developments in 2014.” OECD Network of International Migration Experts, Paris, 1-34.

Valdez-Suiter, Elisabeth, Nancy Rosas-López, and Nayeli Pagaza. 2007. "Gender Differences." In Impacts of Border Enforcement on Mexican Migration: The View from Sending Communities, edited by Wayne A. Cornelius and Jessa M. Lewis. CCIS Anthologies 3. La Jolla: Center for Comparative Immigration Studies.

Vathi, Zana, Veronika Duci, and Elona Dhembo. 2016. "Homeland (Dis)Integrations: Educational Experience, Children and Return Migration to Albania." International Migration, January, n/a-n/a. https://doi.org/10.1111/imig.12230.

Vickstrom, Erik. 2014. "Pathways into Irregular Status Among Senegalese Migrants in Europe." International Migration Review 48 (4):1062-99. https://doi.org/10.1111/imre.12154.

Vullnetari, Julle. 2015. "Albanian Seasonal Work Migration to Greece: A Case of Last Resort?” In Migration in the Southern Balkans: From Ottoman Territory to Globalized Nation States, edited by Hans Vermeulen, Martin Baldwin-Edwards, and Riki van Boeschoten. New York: Springer.

Williams, Allan M., and Vladimir Baláž. 2012. "Migration, Risk, and Uncertainty: Theoretical Perspectives.” Population, Space and Place 18 (2):167-180.

World Bank. 2015. "Albania: Overview.” 2015. http://www.worldbank.org/en/country/albania/overview. 
— . 2016. "World Development Indicators: Albania, Total Population.” 2016. http:// data.worldbank.org/indicator/SP.POP.TOTL/countries/AL?display=graph.

Zaiceva, Anzelika, and Klaus F. Zimmermann. 2008. "Scale, Diversity, and Determinants of Labour Migration in Europe." Oxford Review of Economic Policy 24 (3):427-451. https://doi.org/10.1093/oxrep/grn028. 
Table 1: The Incidence of Unauthorized Migration by Responsibilities, Sex, and Age

\begin{tabular}{llllll}
\hline & No Responsibilities & Responsibilities & Sex (Women) & Sex (Men) & Median Age \\
\hline Authorized migration & $38 \%$ & $55 \%$ & $73 \%$ & $36 \%$ & 28 years \\
Unauthorized migration & $62 \%$ & $45 \%$ & $27 \%$ & $64 \%$ & 26 years \\
\hline Total & $100 \%$ & $100 \%$ & $100 \%$ & $100 \%$ & \\
\hline
\end{tabular}

Notes: all differences are statistically significant at $\mathrm{p}<0.01, \mathrm{~N}=1,878$. 
Table 2: Unauthorized Migration: Odds Ratios from Logistic Regression Models

\begin{tabular}{lcccc}
\hline & Model 1 & Model 2 & Model 3 & Model 4 \\
\hline No Responsibilities (reference) & & & & \\
$\quad$ Responsibilities & 0.916 & 0.913 & 0.940 & 0.927 \\
Age & 0.982 & 0.982 & 0.980 & 0.981 \\
Women (reference) & & & & \\
$\quad$ Men & 4.165 & 4.156 & 4.174 & 4.065 \\
Preparations & 0.402 & 0.396 & 0.405 & 0.405 \\
Poor financial situation & 1.855 & 1.861 & 1.860 & 1.843 \\
Education & & 1.009 & & \\
Migration after 2008 & & & 1.115 & \\
Push factors as reasons to migrate & & & & 1.138 \\
\hline -2LL & 153.17 & 153.15 & 153.10 & 152.77 \\
N & 1,878 & 1,878 & 1,878 & 1,878 \\
\hline
\end{tabular}

Notes: Outcome variable: unauthorized migration. Given are the odds ratios. All coefficients are significant at $\mathrm{p}<0.01$. 
Fig. 1: Interaction Effect Between Age (Risk Taking) and Social Responsibilities

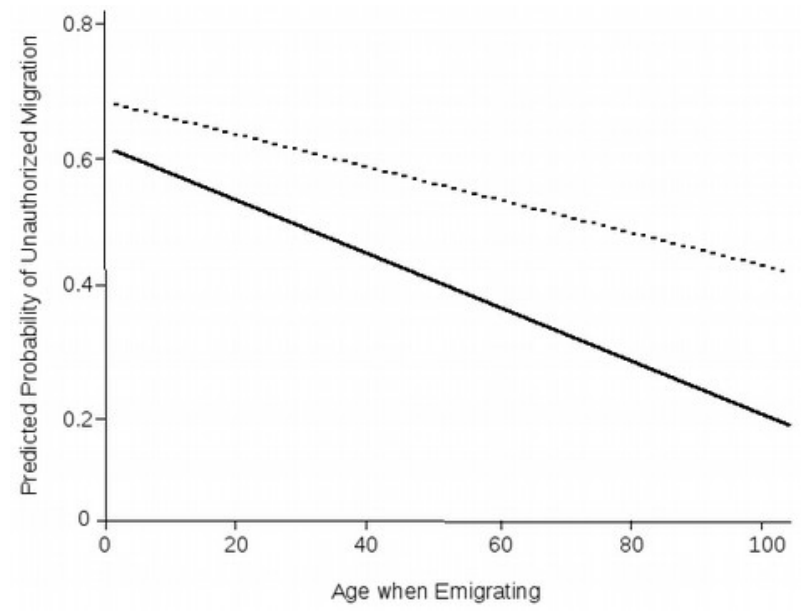

Notes: dotted line $=$ no responsibilities, solid line $=$ with social responsibilities. Outcome variable: unauthorized migration; other variables and specifications as in model 2 in Table 2 above. 


\section{ONLINE SUPPLEMENT}

Table S1: Unauthorized Migration: Non-Linear Terms for Age and Years of Education

\begin{tabular}{|c|c|c|c|c|c|}
\hline & Model S1 & Model S2 & Model S3 & Model S4 & Model S5 \\
\hline \multicolumn{6}{|c|}{ No Responsibilities (reference) } \\
\hline Responsibilities & 0.775 & 0.784 & 0.764 & 0.902 & 0.983 \\
\hline Age & 1.084 & 1.076 & 1.099 & 0.980 & 0.979 \\
\hline Age $^{2}$ & 0.999 & 0.999 & 0.999 & & \\
\hline \multicolumn{6}{|l|}{ Women (reference) } \\
\hline Men & 3.771 & 3.669 & 3.742 & 3.931 & 3.922 \\
\hline Preparations & 0.384 & 0.422 & 0.408 & 0.419 & 0.529 \\
\hline Poor financial situation & 1.810 & 1.771 & 1.777 & 1.830 & 1.747 \\
\hline Education & & 1.270 & 0.963 & 1.476 & \\
\hline Education $^{2}$ & & 0.985 & & 0.979 & \\
\hline \multicolumn{6}{|c|}{ Lower education (reference) } \\
\hline Medium education & & & & & 1.972 \\
\hline Higher education & & & & & 1.790 \\
\hline$-2 \mathrm{LL}$ & 151.15 & 150.25 & 150.93 & 151.67 & 2818.97 \\
\hline $\mathrm{N}$ & 1878 & 1878 & 1878 & 1878 & 1878 \\
\hline
\end{tabular}

Notes: Outcome variable: unauthorized migration. Given are the odds ratios from logistic regression analysis. All coefficients are significant at $\mathrm{p}<0.01$, except 'responsibilities' ( $\mathrm{p}>0.1$ ), medium education $(\mathrm{p}<0.05)$, and higher education $(\mathrm{p}>0.1)$.

Table S2: Unauthorized Migration: Network Variables

\begin{tabular}{lll}
\hline & Model S6 & Model S7 \\
\hline No Responsibilities (reference) & & \\
$\quad$ Responsibilities & 0.952 & 1.219 \\
Age & 0.985 & 0.985 \\
Women (reference) & & \\
$\quad$ Men & 2.946 & 3.614 \\
Preparations & 0.379 & 0.379 \\
Poor financial situation & 1.817 & 1.806 \\
Reasons to migrate & & \\
$\quad$ Join family & 0.277 & 0.270 \\
$\quad$ Join friends & 1.801 & 1.811 \\
Responsibilities * sex & & 0.741 \\
\hline -2LL & 148.72 & 148.65 \\
N & 1878 & 1878 \\
\hline
\end{tabular}

Notes: Outcome variable: unauthorized migration. Given are the odds ratios from logistic regression analysis. All coefficients are significant at $\mathrm{p}<0.01$. 
Table S3: Unauthorized Migration: Interaction between Sex and Responsibilities

\begin{tabular}{|c|c|c|c|c|}
\hline & Model S8 & Model S9 & Model S10 & Model S11 \\
\hline \multicolumn{5}{|l|}{ No Responsibilities (reference) } \\
\hline Responsibilities & 0.902 & 0.892 & 0.912 & 0.928 \\
\hline Age & 0.982 & 0.982 & 0.980 & 0.981 \\
\hline \multicolumn{5}{|l|}{ Women (reference) } \\
\hline Men & 4.112 & 4.075 & 4.099 & 4.070 \\
\hline Responsibilities * sex (interaction) & [1.018] & {$[1.028]$} & {$[1.026]$} & {$[0.996]$} \\
\hline Preparations & 0.402 & 0.396 & 0.405 & 0.405 \\
\hline Poor financial situation & 1.855 & 1.862 & 1.861 & 1.843 \\
\hline Education & & 1.009 & & \\
\hline Migration after 2008 & & & 1.138 & \\
\hline Push factors as reasons to migrate & & & & 1.138 \\
\hline$-2 L L$ & 153.17 & 153.15 & 153.10 & 152.77 \\
\hline $\mathrm{N}$ & 1,878 & 1,878 & 1,878 & 1,878 \\
\hline
\end{tabular}

Notes: Outcome variable: unauthorized migration. Given are the odds ratios from logistic regression analysis. All coefficients are significant at $\mathrm{p}<0.01$, except for the interaction term between responsibilities and sex ( $\mathrm{p}>0.05$ in all models, given in square brackets). 
Table S4: Unauthorized Migration to Greece: Odds Ratios from Logistic Regression

Models

\begin{tabular}{lllll}
\hline & Model G1 & Model G2 & Model G3 & Model G4 \\
\hline No Responsibilities (reference) & & & & \\
$\quad$ Responsibilities & {$[0.901]$} & {$[0.881]$} & {$[0.957]$} & {$[0.911]$} \\
Age & 0.987 & 0.987 & 0.984 & 0.988 \\
Women (reference) & & & & \\
$\quad$ Men & 3.547 & 3.502 & 3.607 & 3.514 \\
Preparations & 0.679 & 0.641 & 0.679 & 0.679 \\
Poor financial situation & 1.690 & 1.713 & 1.702 & 1.656 \\
Education & & {$[1.037]$} & & \\
Migration after 2008 & & & 1.402 & \\
Push factors as reasons to migrate & & & & 1.162 \\
\hline -2LL & 1577.47 & 1574.93 & 1571.90 & 1572.59 \\
$\mathrm{~N}$ & 1,333 & 1,333 & 1,333 & 1,333 \\
\hline
\end{tabular}

Notes: Outcome variable: unauthorized migration. Given are the odds ratios. All coefficients are significant at $\mathrm{p}<0.05$, except those in square brackets. 
Table S5: Unauthorized Migration to Italy: Odds Ratios from Logistic Regression Models

\begin{tabular}{lllll}
\hline & Model I1 & Model I2 & Model I3 & Model I4 \\
\hline No Responsibilities (reference) & & & & \\
$\quad$ Responsibilities & {$[1.266]$} & {$[1.290]$} & {$[1.110]$} & {$[1.251]$} \\
Age & 0.952 & 0.951 & 0.958 & 0.952 \\
Women (reference) & & & & \\
$\quad$ Men & 7.600 & 7.683 & 7.469 & 7.575 \\
Preparations & 0.264 & 0.280 & 0.268 & 0.264 \\
Poor financial situation & 1.613 & 1.597 & 1.660 & 1.622 \\
Education & & {$[0.969]$} & & \\
Migration after 2008 & & & 0.610 & \\
Push factors as reasons to migrate & & & & {$[0.933]$} \\
\hline -2LL & 467.19 & 466.73 & 463.06 & 466.92 \\
N & 441 & 441 & 441 & 441 \\
\hline
\end{tabular}

Notes: Outcome variable: unauthorized migration. Given are the odds ratios. All coefficients are significant at $\mathrm{p}<0.05$, except those in square brackets. 
Table S6: Differentiating Responsibilities and Unauthorized Migration: Odds Ratios from Logistic Regression Models

\begin{tabular}{ll}
\hline & Model 1 \\
\hline $\begin{array}{ll}\text { No Responsibilities (reference) } \\
\text { Married }\end{array}$ & {$[1.133]$} \\
Dependent children & {$[0.836]$} \\
Age & 0.981 \\
Women (reference) & \\
$\quad$ Men & 4.074 \\
Preparations & 0.491 \\
Poor financial situation & 1.781 \\
Education & \\
Migration after 2008 & \\
Push factors as reasons to migrate & \\
\hline -2LL & 2185.70 \\
$\mathrm{~N}$ & 1,878 \\
\hline
\end{tabular}

Notes: Outcome variable: unauthorized migration. Given are the odds ratios. All coefficients are significant at $\mathrm{p}<0.01$, except those in square brackets $(\mathrm{p}>0.1)$. 